\title{
Parasetamolün Tablet Formülasyonu Üzerinde Modern Dağıtıcıların Etkilerinin Íncelenmesi
}

Investigation of the Effect of Modern Disintegrants on the Tablet Formulation of Paracetamole

\author{
Nilüfer TARIMCI*, Tanver DOĞANAY* *, Asuman ERCAN*, \\ Cem ÖZYURT*, Tamer BAYKARA*
}

\section{ÖZET}

Bu çalışmada parasetamolün hem doğrudan basım, hem de yaş granülasyon yöntemi ile değişik tablet formülasyonları hazırlanmış ve bunların optimizasyonu üzerinde çalışılmıştır.

$\mathrm{Bu}$ amaçla, mikrokristalin sellüloz, sodyum nişasta glikolat ve hidrojene hint yağı gibi modern dağıtıcılar nişastanın yanında alternatif olarak kullanılmıştır. Ayrıca bağlayıcı derişkenliğininde yaş granülasyon yönteminde tabletin ve granülelerin fiziko-farmasötik ve fiziko-mekanik özellikleri üzerine etkisi karşılaştırmalı bir şekilde ve istatistiksel olarak incelenmiştir.

Deney sonuçlarına göre, doğrudan basım ile hazırlanan formülün tüm özelliklerinin daha üstün çıkmasına rağmen, yaş yöntem ile hazırlamak ekonomik yönden daha uygun bulunmuştur.

\section{SUMMARY}

In this study, various tablet formulations of paracetamole were prepared using both direct compression and wet granulation method, and then these formulations were optimized.

Redaksiyona verildiği tarih: 21 Mart 1984.

* Farmasötik Teknoloji Ana Bilim Dalı, Eczacılık Fakültesi, Ankara Üniversitesi

** Farmasötik Teknoloji Ana Bilim Dalı, Eczacılık Fakültesi, Gazi Üniversitesi 
For this purpose, modern disintegrants such as microcrystalline cellulose, sodium starch glycolate and hydrogeneted castor oil were used as an alternative to potato starch. In addition, comperative statistical investigations were carried out on the effect of consantration of binding solution on the physico-pharmaceutic and physico-mechanic properties of tablets and granules in wet granulation method.

According to the results of experiments, although all propertis of the formulation prepared by direct compession was superior, it was found that it is economical to use the wet granulation method.

Anahtar Kelimeler: Parasetamol, Tablet Formülasyonu, Granülasyon Teknikleri, Granülelerin Fiziko-mekanik Özellikleri, Çözünme Hizı.

Günümüzün önemli analjeziklerinden olan parasetamol, fenasetinin aktif metabolitleri arasında en az toksik ve en etkili olanıdır $(1,2)$. Bu nedenle birçok ülkede olduğu gibi ülkemizde de fenasetinin yerine geçmiştir. Her ilaç şeklinde olduğu gibi tabletlerde de etken ve yardimcı maddelerin fiziksel, fiziko-kimyasal ve fiziko-farmasötik özellikleri gerek yararlılık açısından, gerekse teknolojik açıdan farklı sonuçlar elde edilmesine neden olmaktadir (3-5).

Etken madde olarak kullanılan parasetamol partikül iriliği ve dağılımına bağlı olarak tablet imalâtında farklı fiziko-mekanik özellikler göstermektedir (6).

$\mathrm{Bu}$ çalışmada, ülkemizde üretilmekte ve yerli ilaç endüstrimiz tarafından kullanılmakta olan parasetamolün tablet formülünün optimizasyonu üzerinde çalışılmıştır. Bu amaçla parasetamol tableti hem doğrudan basım, hem de yaş yöntemle imal edilmiş, kullanılan farklı ve modern dağıtıcı ajanların ve bağlayıcı derişkenliğinin sonuca etkisi karşılaştırmalı olarak incelenmiştir.

\section{DENEL KISIM}

\section{Materyal:}

Parasetamol (Atabay İlaç Sanayii), Sıvı Vazelin (Farmasötik Kalite), Mikrokristalin Sellüloz (Avicel PH 101, FMC Corp.), Patates Nişastası (Farmasötik Kalite), Sodyum Nişasta Glikolat (Primojel, 


\section{N.TARIMCI T.DOĞANAY A.ERCAN C.ÖZYURT T.BAYKARA}

Awebe GMBH), Polivinil Prolidon (Kollidon 30, BASF), Hidrojene Hint Yağ 1 (Cutina HR, Henkel GMBH), Kolloidal Silisyum Dioksit (HDK-V15, Wecker Chemie), Sodyum Klorür (Merck), Hidroklorik Asit (Merck).

\section{Metod:}

1. Parasetamolün partikül iriliği analizi mikroskop yöntemi ile yapılmış ve log-olasılık grafiğine geçirilmiştir (7).

\section{Tabletlerin Hazırlanması:}

Gerek doğrudan basım ve gerekse yaş granülasyon yöntemi ile hazırlanmış olan tabletlerin formülleri ve kodlandırılmaları Tablo 1. de verilmiştir.

Tablo 1. Hazırlanan Tablet Formülleri

\begin{tabular}{|c|c|c|c|c|c|}
\hline \multirow[b]{2}{*}{$\begin{array}{l}\text { Maddeler } \\
(\mathrm{mg} . \text { olarak) }\end{array}$} & \multicolumn{4}{|c|}{ Yaş Yöntem } & \multirow{2}{*}{$\begin{array}{l}\begin{array}{l}\text { Doğrudan } \\
\text { basım }\end{array} \\
\text { A5 }\end{array}$} \\
\hline & $\mathrm{Al}$ & A2 & A3 & A4 & \\
\hline Parasetamol & 325 & 325 & 325 & 325 & 325 \\
\hline Avicel PH 101 & 9 & 9 & 9 & 9 & 110 \\
\hline Patates Nişastası & 15 & 9 & 15 & 9 & 9 \\
\hline Primojel & 3 & 9 & 3 & 9 & 9 \\
\hline Kollidon 30 & 4.7 & 4.7 & 9.4 & 9.4 & \\
\hline Patates Nişastası & 7.45 & 7.45 & 7.45 & 7.45 & - \\
\hline Cutina HR & 7.28 & 7.28 & 7.38 & 7.38 & 8.97 \\
\hline H D K - V 15 & 1.82 & 1.82 & 1.84 & 1.84 & 2.26 \\
\hline
\end{tabular}

2.1. Yaş Granülasyon Yöntemi ile Tabletlerin Hazırlanması.

Mikrokristalin sellüloz, patates nişastası ve primojel küp karıştırıcıda (Erweka, Tip K VI) 20 dev./dak. hızda bir dakika süre ile karıştırılmış, daha sonra, parasetamol geometrik seyreltme yöntemi ile aynı hizda evvela 10 dakika ve sonra 45 dev./dak. da 5 dakika süre ile karıştırılmıştır. Bu toz karışım hamur etme aletinde (Erweka, Tip LK 5) polivinil prolidonun $\% 4$ a/h veya $\% 8$ a/h lik sulu çözeltisi* ilavesi ile hamur haline getirilmiştir. Granüle, salınımlı granülatörün $1.60 \mathrm{~mm}$ gözenek çaplı eleğinden geçirilip, $50^{\circ} \pm 2 \mathrm{C}$ de 1.5 saat süre

* (Bağlayıcı olarak her kazan için 118 g PVP çözeltisi kullanılmış ve bu miktar 4 kısım halinde, her bir seferde eşit olarak katılmıştır). 
ile hava cereyanlı kurutma dolabında kurutulmuştur. Kuruyan granüle bu kez de aynı aletin 1.25 mm gözenek çaplı eleğinden geçirilmiştir. Aynı granüle bir kez daha kurutma dolabında $50^{\circ} \pm 2 \mathrm{C}$ de 30 dakika süre ile tekrar kurutulmuştur. Hesaplanan miktar üzerinden dış faza patates nişastası ilave edilmiş ve küp karıştırıcıda $20 \mathrm{dev}$./dak. da 15 dakika karıştırılmıştır. Bu karışıma daha sonra Gutina HR ilave edilip, aynı devirde bir dakika, sonra da kolloidal silisyum dioksit ilave edilip, yine aynı devirde 5 dakika süre ile karıştırılmıştır.

2.2. Parasetamol Tabletlerinin Doğrudan Basım Yöntemi ile Hazırlanmasi.

Parasetamol, mikrokristalin sellüloz, primojel ve patates nişastası geometrik seyreltme yöntemi ile küp karıştırıcıda 20 dev. /dak. da 30 dakika süre ile karıştırılmıştır. Bu karışıma önce Cutina HR ilave edilip 1 dakika, sonra aynı devirde Kolloidal silisyum dioksit ilave edilip 5 dakika süre ile karıştırılmıştır.

Gerek yaş ve gerekse doğrudan basım yöntemi ile hazırlanmış olan kütleler eksantrik tip. tablet makinasında (Korsh, Tip EKO, B. Almanya) $10 \mathrm{~mm}$ lik tekli tablet zımbası ile ve $36 \mathrm{dev}$./dak. hizda basılmışlardır.

3. Granüle ve Doğrudan Basım Kütlesi Üzerinde Yapılan Kontrollar.

Granülelerin partikül iriliği analizi, $1.0-0.125 \mathrm{~mm}$ ler arasında USP XX ye (8) uygun olan 9 adet standart test eleği ile yapılmıştır. $\mathrm{Bu}$ amaçla vibratör (Retsch, Tip RV) $2 \mathrm{~mm}$ lik titreşim genliğinde 0.5 saat süre ile çalıştırılmıştır. Granülelerin akma özellikleri, akma süresi tayin aletinde (Erweka, Tip GDT) 35 g lık örnekler kullanılarak yapılmış ve işlem her bir örnek için $10 \mathrm{kez}$ yinelenmiştir (9).

Granülelerin yı̆̆ın açısı, yatay düzlemden $10 \mathrm{~cm}$ yüksekliğe yerleştirilmiş boşaltma borusu kesik bir cam huni (kenar çapı $82 \mathrm{~mm}$, kesik ağız iç çapı $7 \mathrm{~mm}$ ) den 40 g granülenin serbest akması ile oluşan yı̆̆ının yükseklik ve çapının ölçülmesi ile hesaplanmıştır (10). Granüle ve doğrudan basım kütlesinin küme dansiteleri ise $25 \mathrm{~g}$ lık kütlenin, 100 ml lik kapaklı bir mezüre huni yardımı ile serbest akıtılması ile saptanmıştır (10). Granülenin $1 \mathrm{~cm}$ yükseklikten 100 vurma (düşürme) sonucu elde edilen hacmi okunmuş, bu işleme 20 vurma daha 
yapılarak devam edilmiştir. İşlem her bir formül için $10 \mathrm{kez}$ yinelelenerek küme ve sıkıştırılmış dansiteler bulunmuştur.

4. Tabletler Üzerinde Yapilan Kontrollar.

Tabletlerin ağırlık sapması, her bir formülden rastgele seçilen 20 tablet üzerinden yapılmıştır (Metler H 10) (11). Tablet kalınlıklıkları mikrometre (Kaefer) ile ölçülmüştür*.

Tabletlerde sertlik kontrolları, basimdan hemen sonra 10 tablet üzerinden (Strong-Cobb, Tip PT 100), ufalanma aşınma kontrolü ise (Roche Friabilatörü), 20 tablet üzerinden ve 4 dakika süre ile yapılmıştır (12).

Dağılma kontrolü, pepsin içermeyen yapay mide ortamında, $37 \pm 1{ }^{\circ} \mathrm{C}$ de (Manesty, Machines LTD) disksiz olarak yapılmış ve her bir formülden alınan 6 tabletin dağılma sürelerinin ortalaması o formülün dağılma süresi olarak kabul edilmiştir.

Çözünme hızı kontrolları, pepsin içermeyen yapay mide ortamında $37 \pm 1{ }^{\circ} \mathrm{C}$ de (Erweka Tip DT) USP XX Paddle Yöntemi kullan1larak yapılmıştır (8). Karıştırma hızı olarak 50 rpm seçilmiş ve her formülden 3 tablet üzerinden deney yapılarak ortalama alınmıştır. Sonuçlar daha önce $242 \mathrm{~nm}$ de hazırlanmış olan kalibrasyon doğrusu yardımı ile değerlendirilip, zamana karşı açı̆̆a çıkan \% yı̆̆ılmalı madde miktarları bulunmuştur.

Tabletlerin etken madde miktar tayini kontrolları, USP XX yöntemine göre her formülden 6 tablet üzerinden yapılmıştır.

Dağılma, çözünme hızı ve etken madde miktar tayini kontrolları Türkiye piyasasında bulunan 2 ayrı parasetamol müstahzarınada uygulanmıştır.

\section{SONUÇ ve TARTIŞMA}

Parasetamolün mikroskopta yapılan partikül iriliği analizinde, -partiküllerin ortalama çapının $4.3 \mu \mathrm{m}$ ve dağılımın geometrik standart sapmasının da 2. 18 olduğu bulunmuştur. Granülelerin partikül irilikleri ve dağılımlarının bağlayıcı \% miktarına göre farklılık gösterdiği

* Tabletlerin basılması, tekli zımba ile yapılmış olduğu için, ayrıca çap ölçülmesine gerek duyulmamıştır. 
değerlendirilen elek analizi sonuçlarına göre saptanmıştır (Al: 360 $\mu \mathrm{m}$, A2: $360 \mu \mathrm{m}$, A 3: $520 \mu \mathrm{m}$, A4: $300 \mu \mathrm{m})$.

Granüle ve doğrudan basım kütlelerinin akma özellikleri Tablo 2. de görülmektedir. Tabloda da belirtildiği gibi, en yüksek akış hızını A4 formülü göstermiştir. Formüllerin akış hızları üzerinde yapılan önemlilik kontrolunda iç fazdaki primojel ve patates nişastası konsantrasyonlarının bu konuda önemli bir fark yaratmadı̆̆ı, buna karşın birer eş olan A1-A3 ( $\mathrm{p}<0.05)$ ve A2-A4 $(\mathrm{p}<0.05)$ arasındaki farkın önemli olduğu bulunmuştur. Buda bize, bağlayıcı derişkenliğindeki farklılığın, granülenin partikül iriliği ve dağılımına etki ettiğini ve bu değişikliğinde granülenin akış hızına yansıdı̆̆ını göstermektedir (13). Aynı durum toz ve granülelerin akma özelliklerinin bir başka ölçütü olan, yığın açısında da kendini göstermiş, yapılan yığın açısı ölçümlerinde eş formüller arasinda (A1-A3, p < 0.05, A2-A4, p < 0.05) anlamlı farklılıklar bulunmuştur.

Tablo 2, de gösterilmiş olan küme dansitesi değerlerinin ortalamaları aynı gözükmesine karşın eş formüller arasında anlamlı farkl111klar mevcuttur (A1-A3, p <0.05 ve A2-A4, p $<0.05)$. Yani farkl1

Tablo 2. Granüle ve Doğrudan Basım Kütlelerinin Akma Özellikleri

\begin{tabular}{|c|c|c|c|c|c|c|}
\hline \multicolumn{2}{|l|}{ Yapilan Kontrollar } & \multicolumn{4}{|c|}{ Yaş Yöntem } & \multirow{2}{*}{$\frac{\text { Doğrudan basım }}{\text { A5 }}$} \\
\hline \multirow{5}{*}{ Akış Hızı (Sn) } & & Al & A2 & A3 & A4 & \\
\hline & $\mathrm{X}$ & 39.5 & 38.4 & 39.1 & 39.8 & - \\
\hline & S.S. & 2.51 & 0.97 & 2.42 & .52 & - \\
\hline & B.S. & 6.34 & 2.45 & 6.2 & 3.92 & - \\
\hline & $\mathrm{X}$ & 0.648 & 0.608 & 0.59 & 0.641 & - \\
\hline \multirow[t]{2}{*}{$\mathrm{Y}_{1 \mathrm{~g}} 1 \mathrm{n}$ Aç1S1 } & S.S. & 0.007 & 0.033 & 0.017 & 0.002 & - \\
\hline & B.S. & 0.999 & 5.50 & 2.94 & 0.3 & - \\
\hline Kü me & $\overrightarrow{\mathrm{X}}$ & 0.514 & 0.513 & 0.511 & 0.51 & 0.487 \\
\hline \multirow[t]{2}{*}{ Dansitesi $\left(\mathrm{g} / \mathrm{cm}_{3}\right)$} & S.S. & 0.459 & 0.699 & 0.316 & 0.817 & 0.852 \\
\hline & B.S. & 0.945 & 1.44 & 0.646 & 1.67 & 1.66 \\
\hline Sıkıştırılmış & $\mathrm{X}$ & 0.583 & 0.585 & 0.59 & 0.595 & 0.676 \\
\hline \multirow[t]{2}{*}{ Dansite I. } & S.S. & 0.669 & 0.483 & 0.529 & 0.624 & 0.500 \\
\hline & B.S. & 1.56 & 1.13 & 1.25 & 2.38 & 1.35 \\
\hline Sıkıştırılmış & $\bar{X}$ & 0.589 & 0.588 & 0.596 & 0.596 & 0.68 \\
\hline \multirow{2}{*}{ Dansite II. } & S.S. & 0.483 & 0.527 & 0.567 & 0.634 & 0.393 \\
\hline & B.S. & 1.131 & 1.24 & 1.35 & 2.38 & 1.07 \\
\hline
\end{tabular}

$\mathrm{X}:$ Ortalama

S.S. : Standart Sapma

B.S. : Bağıl Sapma

- - Yapılan test sonunda herhangi bir değer elde edilememiştir. 
partikül iriliği dağılımının bir yansıması olan küme dansitesi farklılı̆̆ı granülelerin basım öncesi aşamada farklı konsolidasyon gösterdiğinin bir ölçütüdür. Aynı elek büyüklüğünden elenmesine karşın, bu farklı dağılım granüle bağlayıcısının derişkenlik farkının sebep olduğu mekanik direnç sorunudur. Böylece kurutma sonrası granülenin maruz kalacağı mekanik zorlamalara karşı direnci farklıdır. Bu fark granülenin partikül iriliği dağılımının bir fonksiyonu olmaktadır (14). Aynı şekilde 120 vurma (düşürme, tapping) sonucu elde edilen sıkıştırılmış dansitelerde de, partikül iriliği dağılımının farklı oluşuna göre partiküller arası boşlukların doldurulmasında (konsolidasyonunda) farklılıkların çıkmasına sebep olmaktadır (15). Yalnız bu konuda birinci neden partikül iriliği dağılımı olmakla birlikte, ikinci nedeni yani partiküllerin biçiminide (formunu) dikkate almak gerekir (16). Yap1lan çalışmada, her bir granüle ve basım kütlesinin basım öncesi aşamada konsolidasyonu hakkında bir fikir veren Housner eşitliği de (HE: sıkıştırılmış dansite/küme dansitesi) yine 1.0-1.6 arasında çıkmiştır (17).

Formüllere ait ortalama tablet ağırlıklarındaki değişmeler, basılmış oldukları granüle veya doğrudan basım kütlesinin küme dansiteleri ve sıkıştırılmış dansitelerine bağlı olarak ortaya çıkmaktadır (Tab1o 3.). Buna göre en az ağırlık sapması gösteren formül A2 ve A5 formülleri olmaktadır. Aynı formüllerde tablet kalınlıkları da bu kararlı sonucu korumaktadır. Ağırlık sapmaları arasındaki önem kontrollarında Al ve A3 formüllerinin gerek tablet kalınlığı, gerekse ağırlıkları arasında anlamlı bir farklılık bulunamamıştır, $(\mathrm{p}>0.05)$. Yani bağlayıcı derişkenliği ağırlık dağılımlarında anlamlı farklılıklar yaratmamaktadır. Buna karşın A2 ve A4 formülleri incelendiğinde, tablet ağırlıkları ve yükseklikler arasındaki farkın anlamlı olduğu görülmektedir $(\mathrm{p}<0.05)$. Bu sonuç bize Al ve A3 formüllerinde yer alan nişastanın matriks boşluğuna her hacmen doluşunda önemli bir ă̆ırlık değişikliği yapmadığını, buna karşılık nişasta kadar primojel içeren A2 ve A4 formüllerinde ise bağlayıcı derişkenliğinin tabletin fiziko-farmasötik özelliklerini daha önemli ölçüde etkilediğini göstermektedir.

Yaş granülasyon yöntemi ile hazırlanan formüllerin dağılma sürelerinde gruplar arası ve eşler arası anlamlı farklar bulunmuştur (A1-A3 p $<0.05$, A2-A4 p $<0.05$ ). Tablo 3. de de görüldüğü gibi 
Tablo 3. Yaş Granülasyon ve Doğrudan Basım Yöntemi ile Hazırlanan Tabletlerin FizikoFarmasötik Özellikleri

\begin{tabular}{|c|c|c|c|c|c|c|}
\hline \multicolumn{2}{|c|}{ Formül No. } & \multirow{2}{*}{$\begin{array}{c}\begin{array}{l}\text { Tablet } \\
\text { A } \breve{g}_{1} \text { rliğ }_{1} \\
(\mathrm{mg})\end{array} \\
381.80 \\
11.43 \\
2.993\end{array}$} & \multirow{2}{*}{$\begin{array}{c}\begin{array}{c}\text { Tablet } \\
\text { Kalınlı } \\
(\mathrm{mm})\end{array} \\
4.05 \\
0.073 \\
1.802\end{array}$} & \multirow{2}{*}{$\begin{array}{c}\text { Sertlik } \\
\text { (S.C.U.) } \\
13.45 \\
1.716 \\
12.71\end{array}$} & \multirow{2}{*}{$\begin{array}{c}\text { Ufalanma } \\
\text { aşınma } \\
(\%) \\
0.618 \\
2.492 \\
37.62\end{array}$} & \multirow{2}{*}{$\begin{array}{l}\text { Dağılma } \\
\text { süresi (sn) } \\
\begin{array}{r}33.44 \\
2.833 \\
8.47\end{array}\end{array}$} \\
\hline Al & $\begin{array}{l}\text { X. } \\
\text { S.S. } \\
\text { B.S. }\end{array}$ & & & & & \\
\hline A2 & $\begin{array}{l}\text { X } \\
\text { S.S. } \\
\text { B.S. }\end{array}$ & $\begin{array}{r}369.87 \\
3.626 \\
0.980\end{array}$ & $\begin{array}{l}4.01 \\
0.031 \\
0.775\end{array}$ & $\begin{array}{c}14.55 \\
1.102 \\
7.574\end{array}$ & $\begin{array}{l}0.332 \\
0.082 \\
24.75\end{array}$ & $\begin{array}{l}46.7 \\
3.14 \\
6.743\end{array}$ \\
\hline A 3 & $\begin{array}{l}\text { X } \\
\text { S.S. } \\
\text { B.S. }\end{array}$ & $\begin{array}{r}377.38 \\
4.675 \\
1.239\end{array}$ & $\begin{array}{l}4.122 \\
0.126 \\
3.056\end{array}$ & $\begin{array}{l}14.7 \\
0.631 \\
4.293\end{array}$ & $\begin{array}{r}0.307 \\
0.070 \\
22.69\end{array}$ & $\begin{array}{c}41.93 \\
2.927 \\
6.98\end{array}$ \\
\hline A4 & $\begin{array}{l}\text { X } \\
\text { S.S. } \\
\text { B.S. }\end{array}$ & $\begin{array}{r}381.82 \\
4.985 \\
1.305\end{array}$ & $\begin{array}{l}4.20 \\
0.058 \\
1.381\end{array}$ & $\begin{array}{c}14.80 \\
1.852 \\
12.56\end{array}$ & $\begin{array}{l}0.378 \\
0.119 \\
31.45\end{array}$ & $\begin{array}{c}47.66 \\
6.90 \\
14.4\end{array}$ \\
\hline A5 & $\begin{array}{l}\text { X. } \\
\text { S.S. } \\
\text { B.S. }\end{array}$ & $\begin{array}{r}468.55 \\
3.529 \\
0.7453\end{array}$ & $\begin{array}{l}4.90 \\
0.033 \\
0: 673\end{array}$ & $\begin{array}{r}17.35 \\
1.355 \\
7.810\end{array}$ & $\begin{array}{l}0.706 \\
0.065 \\
9.21\end{array}$ & $\begin{array}{r}18.08 \\
2.47 \\
13.66\end{array}$ \\
\hline
\end{tabular}

en kısa zamanda dağılan yaş granülasyon formülü Al olmaktadır. A2 ve A4 formüllerinde patates nişastası yanında primojelin kullanılması bu açıdan bir avantaj getirmemektedir. Durum Al ve A3 formüllerinde de aynıdır. Yani az miktarda primojel ve bunun 5 katı nişasta içeren formül daha çabuk dağılmaktadır. Bunların yanısıra, incelenen iki piyasa preparatında ise ( $\mathrm{P} 1$ ve P2) dağılma süreleri sırası ile $36.3 \mathrm{sn}$. ve 18.7 sn bulunmuştur.

Yine aynı tablo incelendiğinde tablet sertliklerinin birbirlerine oldukça yakın olduğu görülmektedir. Sadece Al formülünde 13.45 S.C.U. bulunmuştur. A3 ve A4 formüllerinde içeriklerin aynı olmasına karşın bağlayıcı derişkenliğinin farklı olması sonucu bir farklılık mevcuttur. Bunun nedeni ise, yüksek derişkenlikte olan bağlayıcının viskozluğu ve bu granülenin basımda yield değerine daha geniş bir basınç aralı̆̆ında erişebilmesi nedeniyle, dağılmanın aynı ölçüde uzamasıdır (18, 19). Doğrudan basım kütlesine gelince, formülde etken madde miktarı aynı olmasına karşı, avicel miktarının 12 misli fazla olması, hem az basınçla fazla sertlik sağlamakta, hem de avicele özgü dağıtma olgusunuda birlikte getirmektedir. Yaş granülasyon formüllerinde en kısa dağılma süresi $33.44 \pm 2.83$ sn çıkarken, burada 18.08 
\pm 2.47 sn olmaktadır. Bu çözünme hızı açısından da istenilen bir sonuçtur. Aynı formülün sertliğide yine yaş granülasyon ile hazırlanan formüllerden farklı çıkmıştır $(20,21)$. Yaş granülasyon formüllerinde dış fazda bir dağıtıcının bulunması lubrikantın dağılma ve çözünme hızındaki olumsuz etkisini önlemek için düşünülmüştür. (Running Powder) (22). Halbuki bu tehlike tablet teknolojisinde daha büyük bir sıklıkla doğrudan tabletleme işlemlerinde ortaya çıkmaktadir. Formüllere dikkat edildiğinde (Tablo 1.) doğrudan basım kütlesinin dış fazda bir dağıtıcı içermediği, buna karşılık lubrikantı diğerlerine göre daha fazla miktarda içerdiği görülmektedir (23).

Ufalanma aşınma sonuçları, bu beş formülde oldukça komplekstir. Çünkü tabletlerin mekanik dirençlerinde ufalanma aşınma testi sadece basınç, sıkıştırmaya (kompresyona) karşı reaksiyon ve tabakalaşmayı içermez. Aynı zamanda tozun fiziksel özelliklerine, bağlayıc1 derişkenliğine, partiküller arası boşluklara, konsolidasyon aşamasındaki basılabilirlik parametresine, zımba-matris ara boşluğuna ve makinanın sıkıştırma hızına bağlıdır (24). Yaptı̆̆ımız çalışmada yukarıda sayılan parametreler tek tek incelenmediğine göre bağlayıcı derişkenliği küçük olan Al ve A2 formülleri arasında, patates nişastasını A2 ye göre daha fazla içeren Al formülünde friabilitenin yüksek çıkması doğaldır.

Hazırlanan beş formül ve incelenen iki piyasa preparatında içerdikleri etken madde miktarları farmakopenin öngördüğü sınırlar içerisinde bulunmuştur (8).

Çözünme hızı sonuçları incelendiği zaman formüllerin hepsinde de etken maddenin tamamının ortamda çözündüğ̈ gözlenmiştir. Sadece A4 formülünde çıkış profili daha yavaş olup, deney süresi sonunda maddenin \% 94 ü çözünmüştür. Şekil 1. de formüllere ait çözünme hızı grafikleri görülmektedir. USP XX Supp II'nin Acetaminophene Tablet monografisi çözünme hızı bölümünde maddenin \% 80 ninin 30 dakika içinde çözünmesi istenmektedir. Ancak çözünme ortamı olarak pH 5.8 fosfat tamponu verilmiştir. Çalışmalarımızda ise daha öncede belirtildiği gibi pepsin içermeyen yapay mide sıvısı öncede belirtildiği gibi pepsin içermeyen yapay mide sıvısı kullanılmıştır. Ancak bu ortamda da etken maddenin çıkışı farmakopenin verdiği sınıra uymaktadır. Sadece bağlayıcı çözelti derişkenliğinin 
Parasetamolün Tablet Formülasyonu...

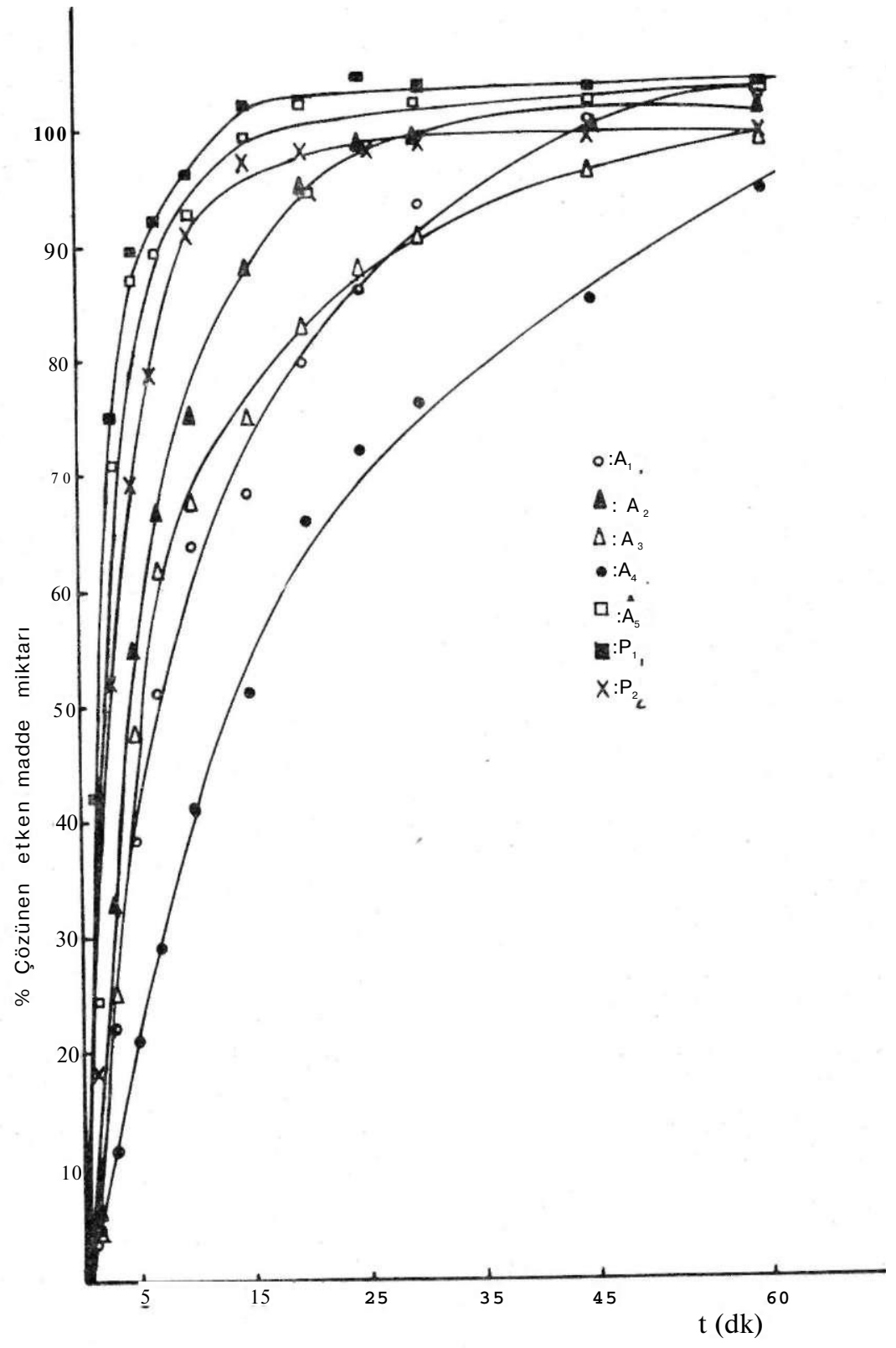

Şekil 1. Çözünme Hızı Profilleri 
daha yüksek olduğu ve dağıtıcıların eş miktarda kullanıldı̆̆ 1 A4 formülünde 30. dakikada maddenin \% 74'ü çıkmıştır. Bu formülün en yüksek sertliği gösteren yaş granülasyon formülü olduğu da dikkate alınırsa, çözünme hızı profilindeki bu yavaş çıkış, açıklığa kavuşmaktadır. Formüllere katılan Primojel ise bu oranda maddenin çözünme hızını çok fazla etkilememiş, ve formüller arasında belirgin bir farklılık yaratmamıştır. Doğrudan basım formülünde, maddenin çıkışı çok hızlı olup, 5. dakika sonunda ortamda çözünen madde miktarı $\%$ 88'e ulaşmıştır. En sert tabletler olmalarına rağmen bu hızlı çıkış avicelin kullanıldı̆̆ lirtilmektedir $(20,25)$.

Diğer taraftan hazırlanan tüm formüllerde etken madde tabletin toplam ağırlı̆̆ının \% 86-87'sini oluşturmaktadır. Etken maddenin bu miktarı formüllerde değişik dağıtıcılar ve farklı derişkenlikte bağlayıcı çözelti kullanmanın yaratacağ 1 fiziko-farmasötik özellikleri tam olarak irdeleme olanağ 1 sağlamamaktadır. Bu yüzden etken maddeyi düşük miktarlarda içeren formüllerde yardımcı maddelerin etkileri daha açık ve belirgin olarak görülebilecektir.

Yapmış olduğumuz çalışmanın sonuçları incelendiğinde, yaş granülasyon yöntemi ile hazırlanmış olan formüllerin basım öncesi testleri arasında sonuca etkili olacak bir farklılık bulunamamıştır. Fakat çözünme hızı sonuçları dikkate alındı̆̆ı zaman bağlayıcıyı az içeren Al ve A2 formüllerinin etken maddeyi ortama verme bakımından daha iyi olduğu gözlenmektedir. Buna karşın bu formüllerin sertlik, dağılma ve diğer teknolojik özellikleri derişik PVP içeren A3 ve A4 formüllerine nazaran daha olumsuz çıkmaktadır. Zira düşük derişkenlikte bağlayıcı içeren formüllerde partikül iriliği dağılımı, elde edilen granülenin kırılganlığının farklı oluşu nedeniyle kontrolsuz bir biçimde değişmiştir. Doğrudan basım formülü olan A5 formülünde ise teknolojik özellikler diğerlerinden daha üstün bulunmuştur. Aynı üstünlük dağılma ve çözünme hızı sonuçlarında da görülmektedir. Bunun başlıca nedeni; formülde yer alan hem doğrudan tabletleme ajanı, hemde kapiller etkili bir dağıtıcı olan mikrokristalin sellülozun \% 23.7 oranında kullanılmış olmasıdır. Ancak bu üstünlük teknolojik açıdan kabul edilse bile, ülke ekonomisi açısından olaya bakıldığında, mikrokristalin sellülozun döviz karşılı̆̆ında yurda girmesi ve formüllerde bazen yüksek oranlarda kullanılmak zorunda kalınması ne- 
deniyle, kendi doğal kaynaklı farmasötik yardımcı maddelerin kullanıldı̆̆ 1 yaş granülasyon formüllerinin diğerlerine yeğ tutulmasını önermekteyiz.

\section{L İ T E R A T Ü R}

1. Goodman, L. S., Gildman, A., The Pharmacological Basis of Therapeutics, 4th. Ed. The MacMillan Company, London and Toronto (1970),

2. Amee, B., Greenblatt, D. J., Acetaminophen, Ann. Int. Med., 87, 202 (1977).

3. Russel, J. K. Jr., Size Reduction, Lieberman, H. A. Lachman L. (Eds), Pharmaceutical Dosage Forms: Tablets, Vol. II, Marcel Decker, Inc., New York, (1981), 80

4. İzgü, E.) Genel ve Endüstriyel Farmasötik Teknoloji II, A. Ü. Eczacılık Fakültesi Yayınları NO. 55, Ankara (1980), 214.

5. Canefe, K., Amoksisilin Trihidrat Tabletlerinin Formülasyon Parametreleri, Stabilite Kinetiği ve Çözünme Hızı Kinetiği ile İlgili Çalışmalar, Doçentlik Tezi, Ankara (1980)

6. Shah M. N., Carroll, M. A., Miller, L. G., An Evaluation of Alternate Sources of directly Compresible Tablet Excipients and Acetaminophone, Pharm. Tech., 7, 45-60 (1983).

7. Edmunson, A. H., Particle-Size Analysis, Bean, H. S., Beckett, A. H., Carless, J. (Eds), Advences in Pharmaceutical. Sciences, Vol. II, Academic Press, New York (1967), p. 94

8. The United States Pharmacopeia (USP XX), 20 th. Ed., Mack Printing Comp., Easton (1980)

9. A. P. V. Fortbildungskurs über Direkttabletticrung, Mainz, W. Germany (1972).

10. Summer, E. D., Particle Size Distribution and Hopper Flow Rates ,J. Pharm. Sci., 55, $1441-1446$ (1966).

11. Türk Farmakopesi 1974, Milli Eğitim Basımevi, Istanbul (1974).

12. Wollish, E. G., Mlodozeniec, A. R., The Mechanical Testing of Tablet Friability, Pharm. Technol, 6, 49-64 (1982).

13. Fonner, D. E., Banker, G. S., Swarbrick, J., Micromeritics of Granular Pharmaceutical Solids I. Physical Properties of Particles Prepared by Five Different Granulation Methods, J. Pharm. Sci., 55, 181-186 (1966).

14. Sucker, H., Test Methods for Granulates, Pharm. Ind., 44, 312-316 (1982).

15. Stanley-Wood, N. G., Shubair, M. S., The Influence of Binder Consantration on the Bond Formation of Pharmaceutical Granules, J. Pharm. Pharmacol., 31, 429-433 (1979).

16. Ridgway, K., Rupp, R., The Effect of Particle Shape on Powder Properties, J. Pharm. Pharmacol, 21, 30 S-39 S (1969). 
17. Dahlinder, L. E., Johanson, M. Sjögren, J., Comparation of Methods for Evaluation of Flow Properties of Powders and Granulates, Drug, Dev. Ind. Pharm-, 8, 455-461 (1982)

18. Lowenthal, W., Burrus, R. A., Mechanism of Action of Strach as a Tablet Disintcgrants IV: Effect of Medicaments and Disintegrants of Mean Pore Diameter and Porosity, J. Pharm. Sci., 6o, 1325-1332, (1971).

19. Schwartz, Z. B., The Instrumented Tablet Press: Uses in Research and Production, Pharm. Technol, 5, 102-103 (1981).

20. Sixsmith, D., The Properties of Tablet Containing Microcrystallince Cellulose, J. Pharm. Pharmacol., 29, 82-90 (1977).

21. Lerk, C. F., Bolhius, G. K., Boer, A. H., Effect of Microcrystalline Cellulose on Liquid Penetration in and Disintegration of Directly Compressed Tablets, J. Pharm. Sci., 68, 205-210 (1979).

22. Sheth, B., Bandelin, F. J., Shangraw, R. E., Compressed Tablets, Lieberman, H. A., Lachman, L. (Eds), Pharmaceutical Dosage Forms: Tablets, Vol. I, Marce1 Decker Inc., New York (1980), p. 135.

23. Bolhius, G. K., Lerk, C. F., Broersma, P., Mixing Action and Evaluation of Tablet Lubricants in Direct Compmression, Drug Devel. Ind. Pharm., 6, 15-33 (1980)

24. Baykara, T., Furosemid Tabletlerinin Biyoyararlılı̆̆ının Formülasyon Çalışmaları ile Geliştirilmesi, Doçentlik Tezi, Ankara (1982)

25. Fox, D., Richman, M. D., Reier, G. E., Shangraw, R., Microcrystalline Cellulose in Tabletting, Drug. Cosmet. Ind., 63, 161-164, 258-261 (1963). 